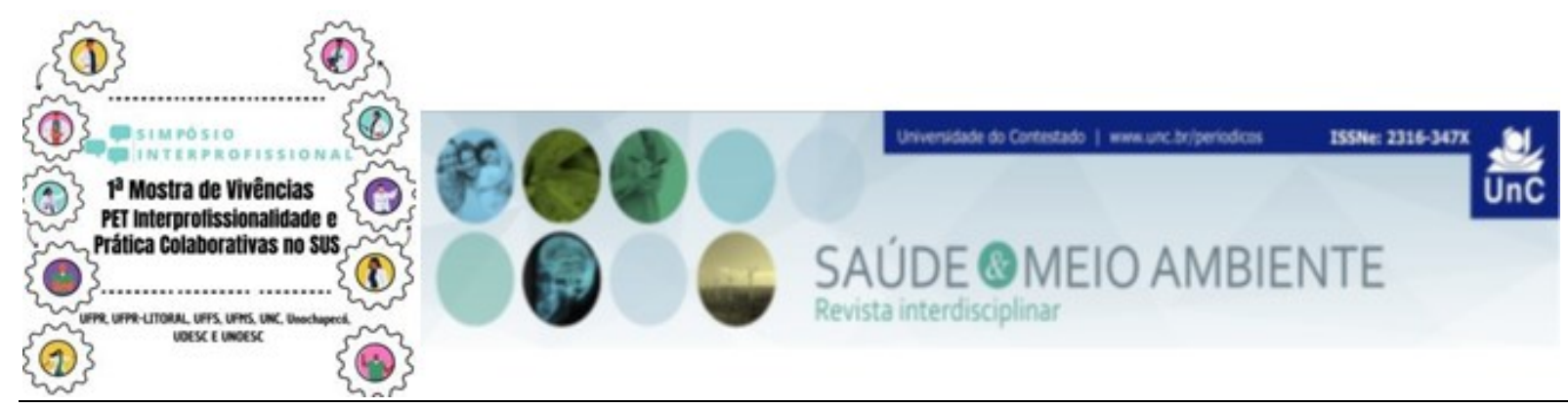

\title{
FORMAÇÃO DOCENTE PARA EDUCAÇÃO INTERPROFISSIONAL EM SAÚDE (EIP) DA TEORIA A PRÁTICA NO ÂMBITO SUS
}

\author{
Rutileia Carvalho Xavier Pinho ${ }^{1}$ \\ José Altamir Batista da Costa²
}

\begin{abstract}
RESUMO
Introdução: No contexto atual, é cada vez mais necessário que pensamos na formação docente interprofissional, para a relevância do trabalho em equipe, práticas colaborativas, na atenção centrada na pessoa sob cuidado, para melhorar a resolutividade das demandas e a qualidade dos serviços de saúde ${ }^{3}$. Isso poderá se tornar realidade se os profissionais de saúde em formação ou na educação permanente forem preparados para trabalhar nesta perspectiva ${ }^{2}$. O processo de formação tem um papel importante no desenvolvimento de competências dos futuros profissionais de saúde, para que possam melhorar a dinâmica do trabalho em saúde, valorizando a colaboração entre os diferentes profissionais ${ }^{1}$. Assim, a EIP é complementar à educação uniprofissional e/ou multiprofissional, no desenvolvimento de atividades curriculares planejadas, isto é, que compõem o currículo dos cursos da saúde. Desta forma, a educação uni e multiprofissional precisa ser revista a partir de uma perspectiva interprofissional para melhorar a prática colaborativa no trabalho em equipe de saúde ${ }^{3}$. Objetivo: Experimentar os caminhos e propor iniciativas de formação docente para atuar no Ensino interprofissional em saúde no âmbito SUS. Metodologia: O presente estudo trata-se de uma revisão de literatura explorativa seguindo os requisitos no contexto desta atualidade, no período de julho a agosto do ano vigente, foram encontrados 12 trabalhos em cada base de dados dentre elas: LILACS, PUBMED, BIREME, SCIELO, foram excluídos 45 artigos, utilizamos a estratégia para a análise e seleção dos dados em consonância com a temática, utilizando os descritores: Formação docente; Interprofissionalidade; Profissionais, SUS. Aplicado na construção do trabalho. Resultados: A EIP insere-se como uma proposta de mudanças para formação docente no âmbito SUS ${ }^{1}$. Esta estratégia procura dar respostas ao fato de que a formação dos profissionais da saúde no Brasil, ao longo do tempo, embasou-se em saberes cada vez mais especializados, distantes de uma prática que privilegie a construção de conhecimentos partilhados

\footnotetext{
${ }^{1}$ Mestre em Educação-Universidade Federal do Tocantins (UFT). Pedagoga-Universidade Federal do Tocantins (UFT). Especialista em Educação e Direitos Humanos-Universidade Federal do Tocantins (UFT). Especialista em Educação de Jovens e Adultos-Universidade Federal do Tocantins (UFT). Especialista em Gênero e Diversidade na Escola-Universidade Federal do Tocantins (UFT).

Tocantins. Brasil. E-mail: rcarvalhouft@gmail.com

${ }^{2}$ Mestrando em Ensino e Ciências da Saúde-Universidade Federal de São Paulo (Unifesp), Esp. em Urgência e Emergência, Universidade Federal de Santa Catarina (UFSC), Esp. Em Nefrologia Multidisciplinar, Universidade Federal do Maranhão (UFMA), Esp. Em Saúde Indígena, Universidade Federal de São Paulo (UNIFESP), Esp. em Enfermagem do Trabalho, Universidade Católica Dom Bosco (UCDB). Tocantins. Brasil. E-mail: enfermeiroaltamir@gmail.com, altamir.batista@unifesp.br
} 
coletivamente ${ }^{3}$. Considerações Finais: Ao pensar nesta formação deve contribuir para o desenvolvimento de profissionais preparados para atuar em consonância com os princípios e as diretrizes do SUS em prol de um sistema de saúde público, universal e equânime, tudo isso começa a fazer sentido ${ }^{3}$. Portanto, se impõe a necessidade da implementação de propostas inovadoras que se proponham a transformar o cenário formativo e compreender os pressupostos teóricos metodológicos que sustentam as possibilidades de mudanças e a formação dos futuros profissionais que irão atuar na gestão, ensino e assistência na relevância da formação (EIP) dentro da perspectiva da interporfissionalidade.

Palavras-chave: Formação docente. Interprofissionalidade. Profissionais. SUS

\section{REFERÊNCIAS}

1. Batista NA, Batista SHSS. Interprofessional education in the teaching of the health professions: shaping practices and knowledge networks. Interface (Botucatu) [internet]. 2016 [acesso em 2020 ago 21]; 20(56):202-204. Disponível em: http://dx.doi.org/10.1590/1807-57622015.0388.

2. Barr H, Koppel I, Reeves S, Hammick M, Freeth D. Eff ec $\Theta$ ve interprofessional education: arguments, assumption \& evidence. Oxford: Blackwell; 2005.

3. Reeves S, Zwarenstein M, Goldman J, Barr H, Freeth D, Hammick M, et al. Interprofessional education: effects on professional practice and health care outcomes. Cochrane Database Syst Rev. 2008. 